\title{
Lei Maria da Penha: percepções de mulheres em contexto de violência intrafamiliar
}

\section{Maria da Penha Law: perceptions of the women in the context of domestic violence}

\section{Ley Maria da Penha: percepciones de mujeres en el contexto de la violencia intrafamiliar}

\section{Recebido: 22/01/2018 \\ Aprovado: 12/08/2018 \\ Publicado: 05/11/2018}

\author{
Tatiana Machiavelli Carmo Souza ${ }^{1}$ \\ Camila Vargas Xavier ${ }^{2}$ \\ Shara Freitas de Sá $^{3}$ \\ Nayra Daniane de Mendonça ${ }^{4}$
}

Este é um estudo qualitativo que tem por objetivo investigar as percepções de mulheres acerca da Lei $\mathrm{n}^{\mathrm{o}}$ 11.340 (Maria da Penha), bem como, sobre a Delegacias Especializadas de Atendimento às Mulheres; realizado de fevereiro de 2015 a março de 2016 na cidade de Jataí/GO, com seis mulheres em situação de violência intrafamiliar que denunciaram os agressores. Os dados foram obtidos por meio de entrevistas semidirigidas, individuais, audiogravadas e transcritas na íntegra, com posterior análise de conteúdo temática. Emergiram 3 categorias: "o conhecimento sobre a Lei Maria da Penha, a descrença na prevenção e o trabalho da DEAM"; "impunidade do autor de agressão, sentimento de injustiça e as consequências da violência"; e, "as expectativas em relação ao outro e a concepção de mulher". Os resultados revelaram o sentimento de insegurança por parte das mulheres, visto que os boletins de ocorrência registrados não resultaram em medidas que punissem os autores ou os impedisse de continuarem ameaçando-as, ou seja, a denúncia não inibiu as violências ou resultou em proteção efetiva. Ao procurarem a delegacia, embora tivessem conhecimentos acerca da existência da lei, as participantes não conheciam seus direitos, especialmente, no que se referia às medidas protetivas.

Descritores: Violência doméstica; Política pública; Família.

This is a qualitative study whose objective is to investigate the perceptions of women about Law 11,340 (Maria da Penha) and about the Specialized Police Offices for Women (DEAM, in Portuguese). It was carried out from February of 2015 to March of 2016 in the city of Jataí/GO, Brazil, with six women in situations of domestic violence that had denounced the aggressors. The data were obtained through semi-directed, individual and audio recorded interviews, that were later transcribed in full, with subsequent analysis of thematic content. Three categories emerged: "Knowledge about the Maria da Penha Law, disbelief on prevention and the work of the DEAM"; "Impunity for the perpetrator of aggression, the feeling of injustice and the consequences of violence"; and "Expectations regarding the other and the woman's conception". The results revealed a feeling of insecurity on the part of women, since the recorded case reports did not result in measures to punish the perpetrators or prevent them from continuing to threaten women, that is, the complaint did not inhibit the violence nor resulted in effective protection. When they sought the police station, although they had knowledge of the existence of the law, the participants were not aware of their rights, especially as regards restraining orders.

Descriptors: Domestic violence; Public policy; Family.

Este es un estudio cualitativo que tiene por objetivo investigar las percepciones de mujeres acerca de la Ley no 11340 (Maria da Penha), así como, sobre Comisarías Especializadas de Atendimiento a las Mujeres; realizado en febrero de 2015 a marzo de 2016 en la ciudad de Jataí/GO, Brasil, con seis mujeres en situación de violencia interfamiliar que denunciaron a los agresores. Los datos fueron obtenidos por medio de entrevistas semi dirigidas, individuales, audio-grabadas y transcritas en la íntegra, con posterior análisis de contenido temático. Surgieron 3 categorías: "el conocimiento sobre la Ley Maria da Penha, el descreimiento en la prevención y el trabajo de la DEAM"; "impunidad del autor de la agresión, sentimiento de injusticia y las consecuencias de la violencia"; y, "las expectativas en relación al otro y la concepción de la mujer". Los resultados revelaron el sentimiento de inseguridad por parte de las mujeres, dado que las denuncias registradas no resultaron en medidas que puniesen a los autores o les impidiese de continuar amenazándolas, o sea, la denuncia no inhibió las violencias o resultó en protección efectiva. Al buscar la comisaría, aunque tuviesen conocimientos acerca de la ley, las participantes no conocían sus derechos, especialmente, en lo que se refería a las medidas protectoras.

Descriptores: Violencia doméstica; Política pública; Familia.

1. Psicóloga. Especialista em Psicopedagogia. Mestre e Doutora em Serviço Social. Professora no curso de Psicologia e no Programa de Pós-graduação em Psicologia da Universidade Federal de Goiás (UFG), Campus Catalão, G0, Brasil. 0RCID: 0000-0001-8834-7022 E-mail: tatimachiavelli@yahoo.com.br

2. Psicóloga. Jataí, GO, Brasil. ORCID: 0000-0001-8332-3099 E-mail: camilavargas.psi@gmail.com

3. Psicóloga. Mestranda em Psicologia pela UFG, GO, Brasil. ORCID: 0000-0003-0309-2548 E-mail: sharafreitasdesa@hotmail.com

4. Psicóloga do Lar Transitório do Município de Jataí, GO, Brasil. ORCID: 0000-0001-8996-2297 E-mail: nayradaniane@hotmail.com 


\section{INTRODUÇÃO}

A violência doméstica e intrafamiliar é um fenômeno originado nas desigualdades de gênero e poder. Gênero, enquanto categoria analítica, diz respeito às construções históricas e sociais acerca do modo de ser homem e mulher, cujos papéis se desenvolvem a partir das aprendizagens na cultura em que estão inseridos ${ }^{1}$.

Historicamente, tem sido designado às mulheres características como docilidade, maternidade, fidelidade e, atividades que as cerceiam no âmbito privado. Em contrapartida, aos homens têm sido indicadas funções de racionalidade, força e posição de dominação no meio familiar; dinâmica que até hoje retroalimenta a lógica patriarcal².

A definição do gênero feminino está aliada à maternidade e ao cuidado familiar, já o masculino, ao trabalho, as atividades na esfera pública e ao provimento da família. Nessa direção, os homens, em seu exercício patriarcal, têm o poder de controlar ou determinar a conduta das mulheres, podendo inclusive puni-las, ainda que elas não estejam em desacordo com as normas sociais ${ }^{3}$.

$\mathrm{Na}$ sociedade patriarcal, machista e misógina, como a brasileira, torna-se permissível a utilização da violência para a supremacia e dominação masculina e para reafirmar a submissão da mulher. Embora a sociedade esteja em constante transformação, ainda promove e apoia comportamentos androcêntricos que reforçam a assimetria das relações entre homens e mulheres, acarretando em graves problemas como a violência no contexto intrafamiliar ${ }^{4}$.

A violência intrafamiliar se refere a qualquer ato de violência que se baseie na diferença de sexo e que resulte em sofrimento, danos físicos, sexuais ou psicológicos à mulher, incluindo ameaças, coerção e privação da liberdade5,6;que tem se constituído em fenômeno social influenciador sobremaneira no modo de viver, adoecer e morrer das mulheres.

A violência doméstica ou intrafamiliar diz respeito às violações e agressões que se dão no âmbito do lar e cujo o autor da agressão, geralmente, trata-se alguém que já manteve ou ainda mantém uma relação íntima de afeto com a vítima. Caracteriza-se de diversos modos, desde marcas visíveis no corpo (violência física) até formas mais sutis, porém não menos importantes, como a violência psicológica, que incide em danos significativos à dinâmica emocional da mulher ${ }^{5,6}$.

A violência intrafamiliar também pode acontecer direcionada à criança, ao adolescente ou a outros membros da família. 0 termo será aqui utilizado para referir-se às violências que são perpetradas por parceiro íntimo à mulher, já que historicamente os homens têm ocupado o lugar de autores e as mulheres de vítimas dessas agressões. 0 uso do termo violência doméstica e intrafamiliar deu-se, também, em consonância com a nomenclatura utilizada na Lei Maria da Penha ${ }^{7,8}$.

Almejando o enfrentamento dos altos índices de violência doméstica e intrafamiliar, o estado brasileiro integrou ações como a criação de normas e padrões de atendimento, aperfeiçoamento da legislação, apoio aos projetos educativos e culturais de prevenção à violência doméstica e ampliação do acesso das mulheres à justiça e aos serviços de segurança pública. Nesse campo, destacam-se os Planos Nacionais de Políticas para as Mulheres, a Lei Maria da Penha, a Política e o Pacto Nacional pelo Enfrentamento à Violência contra as Mulheres, a Norma Técnica do Centro de Atendimento à Mulher em situação de Violência e das Delegacias Especializadas de Atendimento à Mulher6.

A elaboração de medidas específicas por parte do estado para o combate $\mathrm{e}$ enfrentamento da violência doméstica e intrafamiliar foi resultado das reivindicações e mobilizações dos movimentos feministas. Dentre as políticas públicas sancionadas no cenário nacional, destaca-se a lei de $\mathrm{n} \times \mathbf{0} 11.340$, conhecida como Lei Maria da Penha, que passou a vigorar no ano de 2006 e visa prevenir, coibir, punir e erradicar a violência doméstica e intrafamiliar contra a mulher. Dispõe ainda sobre a criação dos Juizados de Violência Doméstica e Familiar contra a Mulher e a aplicação de medidas protetivas de urgência, que são determinações judiciais no 
intuito de ofertar proteção frente à possibilidade de ocorrência de novas condutas violentas, sob pena dos autores sofrerem sanções mediante o descumprimento 5 .

Após doze anos de sua implementação, a Lei Maria da Penha já se tornou um instrumento popularizado no país e o número de denúncias de ameaças e agressões aumentou consideravelmente nos últimos anos, contudo, as ações para a efetivação do atendimento integral às mulheres, bem como a prevenção da ocorrência de novos episódios, têm sido insuficientes. É recorrente o descumprimento das medidas protetivas por parte de autores de agressão e ainda existem dificuldades no que tange a oferta de proteção às mulheres pelos serviços de segurança pública ${ }^{9}$.

A compreensão de que a violência doméstica e intrafamiliar não é fenômeno natural tem exigido esforços para a instrumentalização dos serviços públicos e capacitação dos profissionais de modo que possam identificar as violências e promover ações que se baseiem no reconhecimento das condutas agressivas como uma problemática de ordem sociocultural. A subnotificação também é elemento que interfere diretamente na identificação dos índices de violência doméstica, resultando na invisibilidade da temática e escassez de investimentos por parte do estado para a criação de protocolos e ampliação de serviços especializados ${ }^{10}$.

Mesmo que existam iniciativas por parte do estado na construção de propostas que visem a igualdade entre os sujeitos, além de avanços na criação de instituições voltadas para atenção e proteção às mulheres em situação de violência, as ações não abarcam toda a demanda existente. A Lei Maria da Penha, ainda não alcançou o status de política prioritária no planejamento governamental. Os serviços especializados previstos na lei, como a criação de casas abrigo, delegacias, núcleos de defensoria pública, serviços de saúde e outros, ainda não vigoram em todo o país, concentrando-se nos grandes centros e nas regiões Sul e Sudeste ${ }^{11}$.

Por se tratar de uma temática que envolve inúmeras dimensões, sendo elas jurídicas, econômicas, emocionais, sociais, históricas, políticas, assistenciais e de saúde, vivenciadas de maneira singular em cada contexto e relação interpessoal, é indispensável que diversos saberes se disponham a discutir e teorizar sobre as motivações, estratégias de coibição e práticas que visem a erradicação de condutas violentas. Partindo disso, ao integrar as equipes multiprofissionais, é imprescindível que os psicólogos e outros profissionais se comprometam com a transformação da realidade, rompendo com a ideia de controle social e manutenção de estereótipos, analisando criticamente seus aportes teóricos e metodológicos para que não façam de suas intervenções veículos de perpetuação do machismo e do patriarcado ${ }^{12}$.

Neste contexto, cabe aos profissionais entenderem que a violência intrafamiliar se caracteriza principalmente como uma violação de direitos humanos, permeada pelas desigualdades nas relações de gêneros. Desta forma, a atuação deve se orientar pela oferta de subsídios para a promoção do protagonismo das mulheres, promovendo reflexões, facilitando o processo de conscientização e emancipação para que elas possam identificar situações abusivas, procurar redes de apoio e fortalecer vínculos com a comunidade, construindo relações interpessoais não violentas ${ }^{13}$.

Assim, conhecer as percepções de mulheres em situação de violência sobre a Lei Maria da Penha e o atendimento nas Delegacias Especializadas de Atendimento às Mulheres (DEAM) é importante para propor melhorias nas políticas públicas e nos serviços existentes. Levantamento bibliográfico sobre a temática revelou que o atendimento em delegacias tem perpetuado a injustiça social, dada a baixa resolutividade da força policial ${ }^{14}$.

Embora possa haver acolhimento nas delegacias, não há celeridade na concessão de medidas protetivas e há excesso de burocracia; ainda, a linguagem dos operadores é demasiadamente técnica, comprometendo a compreensão do funcionamento institucional por parte das mulheres $^{15}$. 0 despreparo dos policias no acolhimento das mulheres assinalam a 
importância de fomentar ações de capacitação junto a esses trabalhadores ${ }^{16}$. Diante do exposto, o presente estudo tem por objetivo investigar as percepções de mulheres acerca da Lei no 11.340 (Maria da Penha), bem como, sobre a Delegacias Especializadas de Atendimento às Mulheres.

\section{MÉTODO}

Pautado na metodologia qualitativa, realizouse estudo exploratório ${ }^{18}$ em cidade do sudoeste goiano. Trata-se de parte do projeto integrado "Violência, gênero e família: implicações na psicologia e sociedade".

Foi desenvolvido no período de fevereiro de 2015 a março de 2016. A amostra por conveniência foi composta por seis participantes, todas indicadas pela equipe da DEAM. Como critérios de inclusão, foram escolhidas participantes do sexo feminino, com maioridade penal, em contexto de violência doméstica e intrafamiliar e que efetivaram boletim de ocorrência na Delegacia Especializada de Atendimento à Mulherdo município de Jataí/GO, com vistas a denunciar o autor de agressão. Como critérios de exclusão, ter idade inferior a 18 anos, ter vivenciado violência de gênero cujo autor não tinha parentesco ou vínculo íntimo de afeto e não ter registrado a ocorrência.

A obtenção dos dados deu-se por meio de entrevistas semidirigidas, individuais, audiogravadas e, posteriormente, transcritas na íntegra. As entrevistas foram realizadas por estudantes de psicologia e ocorreram na casa das participantes. As perguntas versavam sobre os dados sociodemográficos, como idade, estado civil, escolaridade, profissão, quantidade de filhos; percepções acerca da Lei Maria da Penha; expectativas ao procurar a delegacia; e medidas protetivas alcançadas.

Sobre a análise de dados, foi utilizada a análise de conteúdo temática, que consiste em uma forma de investigar os dados qualitativos organizando tópicos com assuntos que aparecem com mais frequência ${ }^{17,18}$. As categorias foram formadas a posteriori, a partir da análise das entrevistas e, os dados foram interpretados à luz das teorias de gênero e utilizou-se pseudônimos no intuito de resguardar as identidades.

O estudo contou com aprovação no Comitê de Ética em Pesquisas com Seres Humanos da Universidade Federal de Goiás sob o número 1.919.1805.

\section{RESULTADOS}

As participantes tinham entre 27 e 72 anos de idade e haviam se envolvido em situações de violência perpetrada pelo companheiro, filho ou irmão, isto é, as agressões tinham sido cometidas por pessoas com relações íntimas de afeto. Sobre o nível de escolaridade, tinham entre ensino fundamental incompleto $e$ ensino médio completo. Apenas uma participante não possuía filhos, enquanto as demais tinham entre quatro a nove filhos. Em relação às profissões, havia duas auxiliares em serviços gerais, duas artesãs, uma do lar e uma estava desempregada, informações dispostas na tabela 1.

Tabela 1. Caraterização das participantes. Jataí/GO, agosto de 2015.

\begin{tabular}{c|cccc}
\hline Nome & Escolaridade & Profissão & Filhos & Idade \\
\hline Anne & Ensino Médio Completo & Serviços Gerais & 04 & 45 \\
Diana & Ensino Fundamental Completo & Do lar & - & 26 \\
Jaina & Ensino Fundamental Incompleto & Artesã & 07 & 47 \\
Leona & Ensino Fundamental Completo & Desempregada & 04 & 30 \\
Maria & Ensino Fundamental Incompleto & Artesã & 06 & 72 \\
Vania & Ensino Fundamental Incompleto & Serviços Gerais & 09 & 49 \\
\hline
\end{tabular}

Emergiram três categorias: (1) o conhecimento sobre a Lei Maria da Penha, a descrença na prevenção e o trabalho da DEAM; (2) impunidade do autor de agressão, sentimento de injustiça e as consequências da violência; e (3) as expectativas em relação ao outro e a concepção de mulher.
O conhecimento sobre a Lei Maria da Penha, a descrença na prevenção e o trabalho da DEAM Percebeu-se que as mulheres desconheciam o auxílio propiciado pela Lei Maria da Penha, bem como seus direitos que nela estavam abarcados, defendidos e garantidos; ou seja, 
não tinham acesso às políticas públicas de enfrentamento à violência intrafamiliar:

o que eu conheço assim da Lei Maria da Penha é aquela história daquela mulher que foi machucada, mas assim, eu não sei a profundidade da história. Eu sei que é pra proteger nós mulheres depois do que aconteceu, né? Então assim, eu nunca entrei a fundo na história, por que eu não tinha costume desse negócio que aconteceu com a gente [...] (Vânia).

Pra falar a verdade? Nada. Eu já ouvi falar muitas coisas, uma proteção a favor do caso da mulher né? (Leona).

Vixe eu quase não entendo desses trem assim [...]Até esses dias eu tava vendo um documentário na televisão que fala assim que a pessoa quando tem maus tratos dentro de casa, é pra gente denunciar né, procurar [...] (Jaina)

Ainda, ficou evidenciada a insegurança em relação à concessão de medidas protetivas e sua manutenção. Isso, devido ao receio de as medidas protetivas não serem cumpridas pelo autor de violência, assim como da não efetividade dos instrumentos previstos na legislação vigente:

Não. Não vou mentir, eu tenho medo (referindo-se à medida protetiva) (Leona).

Teve só esses trinta dias de ele não poder se aproximar, aí com trinta dias tinha que reformar de novo (referindo-se a ter de ir à delegacia renovar a medida protetiva de afastamento) a gente não tem nem estrutura emocional pra ficar nessa (Vânia).

$$
\text { Verificou-se, também, }
$$

descumprimento da Lei $11.340 / 06$ por parte dos (ex) companheiros e a reincidência das violências. Essas agressões estavam carregadas de um descrédito quanto à possibilidade de proteção ofertada pela Lei Maria da Penha:

Ele já sabia que ia fazer isso comigo já sabia das consequências que ia passar né? Então ele não teve medo (Leona).

Ele chegou bêbado aqui e queria machucar meu netinho e isso aí eu não aceito [...] Eu entrei no meio e ele queria me enfiar uma... chave de fenda, falou que ia me matare ia matar (fato ocorrido tempos depois de o sujeito ter sido levado à delegacia por denúncia da parte da entrevistada) (Jaina).

Ademais, mesmo com as intempéries ressaltadas nos discursos, constatou-se contentamento das mulheres com o atendimento - realizado por uma mulher - na DEAM. Entretanto, evidenciou-se incômodo das entrevistadas em relação à abordagem dos policiais frente à situação de violência: ótimo, no dia anterior eu fui mais cedo lá (na Delegacia), conversei com a policial ela me atendeu super bem, foi muito gentil comigo [...] eu fui conversei com a delegada e ela me atendeu muito bem (Jaina).
Foi muito bom, como diz o outro, não tem nem o que falar né? Acho que no momento o que eles tinham que fazer ali é o que eles estavam fazendo (sobre o atendimento na Delegacia) (Leona).

Foi bom né [...] Eles fizeram o boletim (Anne).

Eu conversando com o policial que veio aqui, que a gente precisou dele, ele disse: "Vocês peguem e dá um couro aí depois liga pra gente". Eu não achei aquilo ali certo (Vânia).

Eles vieram, (policiais) a gente até então tentou procurar ele, mas não achamos (Leona).

Impunidade do autor de agressão, sentimento de injustiça e as consequências da violência

Foram percebidas consequências emocionais, sociais e estruturais na vida das mulheres advindas da falta de punibilidade das ações dos autores de violência, distanciando-as da garantia de seus direitos:

Enquanto ele vive na liberdade eu vivo no medo, um medo que infelizmente eu sempre vou ter (Leona).

Eu quero é que a justiça aja com rigor por que já ta desestruturando minha família, quero que seja feito algo a mais (Vânia).

Ah eu esperava que ia acontecer as mesmas coisas igual aconteceu das outras vezes. Ele entrava num dia (referindo-se ao cárcere) e com 3 ou 4 dias já tava na rua, ou tinha vezes que não ficava nem isso (Jaina).

Nessa questão da mensagem (o acusado mandava mensagens de celular tentando contato com a vítima) eu tenho medo de ir lá (na Delegacia) falar alguma coisa e nada ser feito, por que até então, nos dias ele havia pedido pra mim retirar a queixa entendeu? Aí ele fala por mensagem que eu destruí a vida dele entendeu? Ele fala que eu destruí [...] Então, e se eu for lá e mostrar essas mensagens? Vai resolver? Ou será que vai piorar? (Leona).

Constatou-se sofrimento das participantes acarretado pela violência vivenciada e pela insegurança em relação aos instrumentos ofertados pela Lei 11.340/06, a exemplo do enclausuramento por medo de reincidência:

Não saio sozinha também, quando eu vou sair eu saio sempre com alguém [...] Eu fico aqui em casa, eu fico só, eu fico sempre com a porta fechada, não é pra todo mundo que eu abro a porta [...] Eu tenho um trauma até do meu namorado falar comigo. Pra te falar a verdade às vezes eu tenho vontade de terminar com meu namorado, mas não tenho nem coragem. Tenho medo de vir a acontecer isso novamente [...] Tem hora que devido a eu ficar muito nervosa, não sei se é por causa do trauma, eu até vou fazer um exame de tomografia, às vezes coisas que eu falo, eu nem lembro. Às vezes eu falo uma coisa pra você aqui agora e amanhã... Às vezes até no mesmo momento, todo mundo fala "Você não lembra de ter falado isso?" E eu falo que não (Leona).

Percebeu-se que a situação de violência transpassou a relação do casal, 
afetando todo o contexto familiar, as relações entre os membros, a relação com os filhos e a dinâmica de vida familiar:

Fica uma situação bem complicada que afeta nossa família, filhos, é uma desestruturação total da família (Vânia).

As meninas não querem, minhas outras duas meninas não quererem ele aqui dentro de casa mais [...] A mais nova (filha) não gosta dele, ele bateu nela [...] (Jaina).

As expectativas em relação ao outro $e$ a concepção de mulher

Verificou-se que as violências acarretaram impacto financeiro e interpessoal, fazendo com que as participantes se responsabilizassem pela criação dos filhos e pela manutenção da casa. Ao mesmo tempo que assumiram esse ônus, essa experiência permitiu o enfrentamento da violência:

Eu criei 6 filhos sozinha, e crio até hoje, isso aqui tudo, esse pouquinho que vocês veem aqui (referindo-se a casa em construção) é trabalho meu, suor meu (Vânia).

Eu que pago a despesa tudo sozinha, eu pago luz sozinha, pago aluguel sozinha [...] (Maria).

As participantes destacaram que a relação entre pai e filho foi fator significativo para a reconciliação conjugal e manutenção do casamento/união estável. Dessa forma, as expectativas em torno de manter uma família nos padrões burguês e nuclear, contribuíram para a permanência afetiva-sexual junto ao autor de violência e, em alguns casos, da própria violência intrafamiliar:

Por que assim, tinha o pai dos meus filhos né, a gente já tava separado há mais de ano, só que tem um cômodo no fundo e eu dei pra ele morar ali, que ele foi preso por causa da Maria da Penha depois saiu rapidão, não virou nada. Aí ele pediu pra morar aqui, que ia melhorar ia mudar e pediu pra morar pra voltar (Jaina).

Eu pensei assim: mais uma né? (referindo-se a filha mais nova que cresceria longe do pai) Aí aquele pai foi se aproximando, coração doce, foi conversando com a minha filha mais velha, que não era assim, que tinha se arrependido, que aquilo não era papel verdadeiramente de homem [...] Por que eu acho que você errar uma vez você tem o direito, igual aconteceu aqui em casa, de ter oportunidade de a pessoa... a gente olha e acha que o coração da pessoa mudou [...] (referindo-se a ter dado uma chance ao autor da agressão) (Vânia).

\section{DISCUSSÃO}

Entender as especificidades da violência doméstica, conhecendo os tipos de agressões, o ciclo que as mantêm e as políticas públicas disponíveis para enfrentamento da problemática, pode auxiliar as mulheres a se apropriarem dos seus direitos, ampliando o exercício da cidadania.

Neste sentido, verificou-se que as participantes possuíam informações genéricas e superficiais acerca da Lei Maria da Penha, desconhecendo, em especial, as determinações estipuladas pelas medidas protetivas e suas finalidades. Como verificado em outros estudos ${ }^{15,19}$, elas sabiam da existência da lei, mas não conheciam seus direitos.

Observou-se, ainda, dificuldade em discriminar o espaço onde o serviço é ofertado (DEAM) e as deliberações jurídicas que regulamentam as sanções frente à ocorrência da violência doméstica praticada contra mulheres (lei propriamente dita).

A Lei Maria da Penha modificou a forma de compreender os casos de violência doméstica no Brasil, fazendo com que as condutas dos autores de agressão passassem a ser investigadas e as mulheres resguardadas por instrumentos específicos, anteriormente descritos como crime de menor potencial ofensivo, com sanções irrisórias ${ }^{20}$.

Em relação às participantes que tiveram as medidas protetivas de afastamento concedidas, elas afirmaram que não se sentiam seguras, relatando o medo de que os homens cometessem outras agressões. É certo que as determinações coercitivas não são capazes de reduzir os índices de violência doméstica e intrafamiliar, visto que é necessário viabilizar ações educativas e preventivas que possibilitem outros significados às masculinidades e feminilidades, resultando em relações não violentas ${ }^{21}$.

Ao serem questionadas sobre a capacidade da Lei Maria da Penha prevenir a ocorrência de violência doméstica, as participantes responderam positivamente, entretanto, percebeu-se contradição em suas argumentações dado receio em relação à reincidência das agressões, bem como ao desgaste emocional resultante da burocracia para a concessão do respaldo jurídico a longo prazo. Estudos semelhantes apontaram que as mulheres acreditam na funcionalidade da referida lei, mas consideravam-na motivadora 
de falsas expectativas às vítimas, dada morosidade do processo legal ${ }^{14,22}$.

A eficácia das ações de prevenção e redução da violência doméstica e de gênero dependem de iniciativas multidisciplinares e multiprofissionais, dada a complexidade do fenômeno e seus desdobramentos ${ }^{12}$. Tal afirmativa remete à importância da intersetorialidade, objetivando não apenas o enfrentamento à violência através de iniciativas de punição, mas de prevenção e conscientização, subsidiando mudanças sociais que visem à garantia e ampliação dos direitos das mulheres.

Além disso, são necessárias discussões que fomentem o combate à desigualdade $\mathrm{e}$ discriminação entre os gêneros, bem como a garantia de atendimento qualificado $\mathrm{e}$ humanizado àquelas que estiverem em situação de violência ${ }^{23}$.

As falas das entrevistadas revelaram, por um lado, o contentamento com o atendimento recebido ao solicitarem auxílio na DEAM; em contrapartida, a insatisfação com a abordagem dos policiais que se deslocaram até as suas residências para atenderem as ocorrências. Quanto à recepção na delegacia, elas atribuíram o acolhimento satisfatório e o tratamento respeitoso à oferta do serviço e o atendimento ter sido realizado por profissionais mulheres.

Em relação ao atendimento em domicílio, as participantes queixaram-se sobre o tratamento dos policiais após elas relatarem o episódio de violência, frisando o despreparo dos mesmos em escutá-las e acolhê-las. A esse respeito, a ausência de capacitação para acolher a mulher em situação de violência pode ocasionar em uma abordagem pautada em preconceitos e concepções machistas, resultando em uma situação de revitimização da mulher já em sofrimento e desencorajando-a a prosseguir com os procedimentos, como a realização da denúncia15,16,24.

Os relatos das entrevistadas revelaram a importância de treinamentos e capacitação para os profissionais que lidam com situações de violência doméstica e intrafamiliar, buscando erradicar os julgamentos moralizantes e machistas, que corroboram para a diminuição das denúncias, sendo também uma prática violenta em desfavor das mulheres. Dessa forma, elas devem ser visualizadas como sujeitos de direitos, submetidas a uma escuta atenta, qualificada e acolhedora por parte dos servidores dos serviços públicos, de forma a propiciar o rompimento com o silêncio, isolamento e atos de violência, aos quais estão subjugadas ${ }^{25}$.

A violência doméstica, quando negligenciada, pode gerar sofrimento constante para a mulher. Segundo as participantes, a falta de amparo dada pela lei e pelo atendimento recebido na DEAM aumentou os sentimentos de incerteza e de insegurança. Somado a isso, apontaram que os autores das agressões não eram punidos, mesmo após a efetivação da denúncia e, ainda, que as ameaças não cessavam. É ínfima a quantidade de autores responsabilizados pela prática de violência doméstica e intrafamiliar; em mais da metade dos casos denunciados, as ocorrências não são instauradas e, portanto, não resultaram em investigação ${ }^{20}$. Nesse caminho, a incerteza da punição faz com que $10 \%$ das mulheres agredidas optem por não procurar veículos legais para o registro da ocorrência ${ }^{19}$.

Além da incerteza sobre a punição, observou-se, por meio dos discursos, que os agressores continuavam realizando ameaças, exigindo que as mulheres retirassem a queixa e/ou não denunciassem o descumprimento das medidas protetivas de afastamento, evidenciando a fragilidade e ineficiência de tais determinações no que concerne à erradicação da prática de violência.

Percebe-se que a aplicação da lei na forma de medida protetiva de afastamento não é o suficiente para cessar a violência. A punição mais rigorosa e a probabilidade maior de condenação através da Lei Maria da Penha podem diminuir as chances de o indivíduo agressivo perpetrar o crime $^{26}$. Em contrapartida, com o passar do tempo, é razoável imaginar que haja uma diminuição das crenças dos ofensores em potencial no sentido de uma maior punição. Com isso, talvez o efeito da Lei Maria da Penha não tenha se dado de forma a prevenir a incidência ou reincidência da violência. 
Os apontamentos realizados pelas entrevistadas apontam o medo de acessarem a delegacia para relatar o contato do autor, bem como o cerceamento no qual elas eram subordinadas, visto que acabavam confinadas ao espaço doméstico por receio de que o exparceiro cometesse novas violências. A Lei Maria da Penha é vista como um avanço no que tange a garantia de direitos femininos, mas medidas protetivas têm valor simbólico, não garantindo por si só a não reincidência de violências ${ }^{9}$. Acrescenta-se que, o deferimento indiscriminado deste recurso culminava em sua banalização, colocando em xeque os eventuais riscos que as mulheres sofriam.

As consequências dos episódios de violência não se esgotam na relação entre a mulher e o autor da agressão, mas resulta no envolvimento de outros sujeitos que estão inseridos no contexto em que os episódios ocorrem. Desse modo, o auxílio familiar em situações de violência doméstica torna-se imprescindível, já que a mulher, muitas vezes, necessita de redes de apoio para perceber e enfrentar o contexto violento em que está inserida ${ }^{25}$. As autoras apontaram, ainda, que parte das ocorrências registradas, havia sido impulsionada por insistência da família e a efetivação do boletim de ocorrência funcionava como uma forma de iniciar o rompimento da relação abusiva.

A Lei Maria da Penha prevê que a mulher em situação de violência deve ser encaminhada a programas e serviços de proteção social, incluindo atendimento psicológico e inserção em programas assistenciais do governo federal, quando necessário, especialmente pelo sofrimento gerado pelas agressões e a existência de vulnerabilidades diversas vivenciadas pelas famílias ${ }^{20}$.

Notou-se, pelos discursos das entrevistadas, que os encaminhamentos aos serviços públicos e inserção em programas não estavam sendo realizados. A insuficiência de políticas públicas, que priorizem o atendimento psicológico, causa enorme prejuízo à vida das mulheres, visto que o acompanhamento especializado poderia amenizar de forma significativa as consequências emocionais advindas dos episódios de violência.

Observou-se que, embora as participantes tenham pontuado que não possuíam recursos para enfrentar o contexto violento em que estavam inseridas, afirmaram que se responsabilizavam sozinhas pelo custeio das despesas do lar e o cuidado com os filhos.

Tal fato demonstra uma possível mudança frente aos antigos moldes patriarcais da sociedade, remetendo à constituição familiar matriarcal, em que não há um homem provedor e a figura feminina ocupa uma posição de protagonista na construção e manutenção do contexto vivencial; aqui se tratando do âmbito doméstico ${ }^{27}$.

Os espaços designados às mulheres têm sofrido inúmeras mudanças ao longo dos anos. Aliada às transformações econômicas, têm-se constituído uma nova concepção do papel feminino na sociedade, embora com resistências, na qual as mulheres vêm conquistando maior representatividade social.

A dinâmica relacional é constituída em cada momento histórico-cultural, bem como os discursos são construídos e modificados em sua historicidade, caminhando, ainda que paulatinamente, para a desconstrução de lugares tradicionalmente destinados às mulheres e em direção à igualdade de gênero; a exemplo a inserção da mulher no mercado de trabalho ${ }^{28,29}$.

Com relação às participantes que sofreram agressão perpetrada pelo parceiro, a separação definitiva foi resultante da reincidência das violências, frisando o descumprimento das promessas de mudanças de conduta por parte dele, o que exemplifica o chamado ciclo de violência.

O sistema que teoriza a maneira com que as relações abusivas se mantém é dividida em três fases: a tensão, que abarca violência psicológica, desrespeito, intimidações, abusos verbais, destruição de documentos, constrangimento público, culpabilização da mulher pelos conflitos familiares; a explosão, na qual ocorre a violência física propriamente dita, seguida pelas juras por parte do autor de 
que tal episódio não mais ocorrerá; e, depois disto, a reconciliação, quando acontece a chamada lua de mel, momento em que a relação fica estável, até que novos comportamentos agressivos voltem a ser praticados $^{13}$.

Os fatores culturais e de gênero são características associadas à violência doméstica e que podem favorecer a permanência da mulher na relação agressiva ${ }^{25}$. Persistir em um relacionamento, após contínuos acontecimentos de violência, ou voltar à relação após a separação, é frequente na vida de mulheres que sofrem violência conjugal ${ }^{30}$.

Assim, amenizar as condutas realizadas pelos autores de agressão e fazer com que as mulheres acreditem na importância do convívio familiar tradicional, sentindo-se culpadas pela suposta separação entre o pai e seus dependentes são condutas recorrentes nas famílias que vivenciam violência.

\section{CONCLUSÃO}

A violência doméstica e intrafamiliar é resultante de uma construção histórica, portanto, é possível a desconstrução. Para tanto, é importante e necessário que, desde a infância, os indivíduos sejam instruídos através de estratégias educacionais e informativas para que as relações entre homens e mulheres não sejam permeadas por comportamentos machistas e atos de violência e, especialmente, que vivenciem relações de poder igualitárias. No Brasil, a promulgação da Lei Maria da Penha foi um grande passo para o enfrentamento da violência.

Mesmo com os avanços assegurados pela lei, constatou-se que as mulheres continuam sendo ameaçadas pelos autores das agressões após terem feito a denúncia e as medidas de afastamento terem sido expedidas. Essa situação corrobora para que as mulheres tenham suas vidas permeadas por sentimentos constantes de insegurança e para o descrédito frente às políticas públicas.

Percebeu-se que as mulheres não acreditavam que a violência pudesse ser prevenida somente pela existência da lei, pois isso não impedia o ex-companheiro de cometer novos episódios de violência. Além disso, as medidas protetivas não se faziam suficientes para a condição de segurança.

Outro ponto importante a ser destacado foi a escassez de equipamentos estruturados e instituições de apoio a mulheres em contexto de violência - como, por exemplo, o Juizado de Violência Doméstica e Familiar contra a Mulher, a Casa abrigo e de passagem, os Centros de Referência, e outros e, principalmente serviços de cunho psicológico ou de assistência social, como é previsto na Lei Maria da Penha.

A criação da Lei Maria da Penha tem dado visibilidade à violência doméstica e intrafamiliar contra a mulher, mas muito ainda precisa ser feito para que o fenômeno tenha efetiva erradicação satisfatória.

É necessária ampla divulgação, para que a população conheça seus direitos e deveres, bem como possa lutar por julgamentos justos, punições adequadas e, imprescindivelmente, pela igualdade de gênero. Ao ter suas propostas de fato cumpridas, a referida lei poderá atuar de forma preventiva e as mulheres poderão ter seus direitos preservados.

\section{REFERÊNCIAS}

1. Scott J. Gênero: uma categoria útil de análise histórica. Educ Real. 1990; 2(20):71-99.

2. Saffioti HI. Já se mete a colher em briga de marido e mulher. São Paulo em Perspectiva 1999; 13(4):82-91.

3. Saffioti HI. Contribuições feministas para o estudo da violência de gênero. Cad Pagu. 2001; (16):115-36.

4. Franzoi NM, Fonseca RMGS, Guedes RN. Violência de gênero: concepções de profissionais das equipes de saúde da família. Rev Latinoam Enferm. 2011; 19(3):589-97.

5. Presidência da República (Brasil). Lei no 11.340, de 7 de agosto de 2006. Cria mecanismos para coibir a violência doméstica e familiar contra a mulher, nos termos do $\S 80$ do art. 226 da Constituição Federal, da Convenção sobre a Eliminação de Todas as Formas de Discriminação contra as Mulheres e da Convenção Interamericana para Prevenir, Punir e Erradicar a Violência contra a Mulher; dispõe sobre a criação dos Juizados de 
Violência Doméstica e Familiar contra a Mulher; altera o Código de Processo Penal, o Código Penal e a Lei de Execução Penal; e dá outras providências [Internet]. D.O.U., Brasília, DF, 8 ago 2006 [citado em: 27 mar 2015]. Disponível em: http://www.planalto.gov.br/ccivil_03/_ato20 04-2006/2006/lei/l11340.htm

6. Presidência da República (Br). Secretaria de Políticas para as Mulheres. Política nacional de enfrentamento à violência contra as mulheres [Internet]. Brasília, DF: Secretaria Nacional de Enfrentamento à Violência contra as Mulheres; 2011 [citado em 10 abr 2015]. Disponível em: http://www.spm.gov.br/sobre/publicacoes/ publicacoes/2011/politica-nacional

7. Bragagnolo RI, Lago MCS, Rifiotis T. Estudo dos modos de produção de justiça da Lei Maria da Penha em Santa Catarina. Estud Fem. 2015; 23(2):601-17.

8. Santos CM, Izumino WP. Violência contra as mulheres e violência de gênero: notas sobre estudos feministas no Brasil. Estud Interdiscip Am Lat Caribe. 2005; 16(1):147-64.

9. Meneghel SZ, Mueller B, ColaziolME, Quadros MM. Repercussões da Lei Maria da Penha no enfrentamento da violência de gênero. Ciênc Saúde Colet. 2013; 18(3):691700.

10. Silva MCM, Brito AM, Araújo AL, Abath MB. Caracterização dos casos de violência física, psicológica, sexual e negligências notificados em Recife, Pernambuco. Epidemiol Serv Saúde. 2012; 22(3):403-12.

11. Calazans M, Cortes I. O processo de criação, aprovação e implementação da Lei Maria da Penha. In: Campos CH. Lei Maria da Penha comentada em uma perspectiva jurídico feminista. Rio de Janeiro: Lumen Juris; 2011. p. 39-64.

12. Guimarães MC. A formação pessoal de psicólogos/as e o trabalho com violência doméstica contra a mulher. [dissertação]. Brasília, DF: Instituto de Psicologia, Universidade de Brasília/UnB; 2014. 128p.

13. Centro de Referências Técnicas em Psicologia e Políticas Públicas. Referências técnicas para a atuação de psicólogas (os) em programas de atenção à mulher em situação de violência. Brasília, DF: Conselho Federal de Psicologia; 2012. 82p.

14. Santi LN, Nakano MAS, Lettiere A. Percepção de mulheres em situação de violência sobre o suporte e apoio recebido em seu contexto social. Texto \& Contexto Enferm. 2010; 19(3):417-24.

15. Silva SM, Santos AL, Gonçalves AOM, Nicário JJ. "Fala Maria porque é de lei": a percepção das mulheres sobre a implementação da Lei Maria da Penha em Salvador/BA. Rev Feminismos. 2016; 4(1):156-67.

16. Carvalho AM, Souza TMC. Mulheres em situação de violência e suas percepções sobre uma DEAM. Rev Psicol Comunidade. 2016; 1(1):79-100.

17. Gibbs G. Análise de dados qualitativos. Porto Alegre, RS: Artmed; 2009. 198p.

18. Minayo MCS. O desafio do conhecimento: pesquisa qualitativa em saúde. 7ed. São Paulo: Hucitec; 2000. 406p.

19. Senado Federal (Brasil). Violência doméstica e familiar contra a mulher. Brasília, DF: Senado Federal; 2015. 81p.

20. Carneiro AA, Fraga CK. A Lei Maria da Penha e a proteção legal à mulher vítima em São Borja no Rio Grande do Sul: da violência denunciada à violência silenciada. ServSoc Soc. 2012; (110):369-97.

21. Amaral NA, Amaral CA, Amaral TLM. Mortalidade feminina e anos de vida perdidos por homicídio/agressão em capital brasileira após promulgação da Lei Maria da Penha. Texto \& Contexto Enferm. 2013; 22(4):980-8.

22. Monteiro M, Antunes BM. Vozes veladas: discursos de mulheres em situação de violência conjugal e de funcionários de uma delegacia especializada no atendimento à mulher (DEAM). In: Seminário Internacional Fazendo Gênero 10: desafios atuais dos feminismos; 2013 set; Florianópolis, SC. Florianópolis: UFSC; 2013. p. 1-12.

23. Cavalcanti PB, Oliveira RD, Carvalho RN, Araújo AP, Miranda APRS. A violência contra a mulher na sociedade brasileira: as demandas transformadas em políticas públicas e a relevância de ações intersetoriais. Vértices (Campos dos Goitacazes). 2014; 16(3):13962. 
24. Martins EPS, Bertoline VL. Violência contra mulher: diferenças e semelhanças no atendimento policial militar, na perspectiva de gênero. Homens do Mato, Rev Cient Pesqui Segur Pública. 2013; 10:52-67.

25. Souza TMC, Moraes FO. Violência contra a mulher e família. Rev Psicol Comunidade. 2015; 7(1):37-62.

26. Cerqueira D, Matos MVM, Martins APA, Pinto Junior J. Texto para discussão: avaliando a efetividade da Lei Maria da Penha. Brasília, DF; Rio de Janeiro: Ipea; 2015. 44p.

27. Hita MG. A casa das mulheres n'outro terreiro: famílias matriarcais em Salvador-BA. Salvador: Edufba; 2014. 513 p.

28. Moraes E. Ser mulher na atualidade: a representação discursiva da identidade feminina em quadros humorísticos de maitena. In: Tasso I, Navarro P, organizadores.
Produção de identidades e processos de subjetivação em práticas discursivas. Maringá: Eduem; 2012. p. 259-285.

29. Simões FIW, Hashimoto F. Mulher, mercado de trabalho e as configurações familiares do século XX. Vozes dos Vales. 2012; 2(1):1-25.

30. Cardoso GFO. Violência doméstica: o que a realidade ensina? [Monografia]. Brasília, DF: Faculdade Ciências da Educação e Saúde, Centro Universitário de Brasília; 2014. 64p.

CONTRIBUIÇÕES
Tatiana Machiavelli Carmo Souza e
Camila Vargas Xavier contribuíram
igualmente em todas as etapas do estudo.
Nayra Daniane de Mendonça e Shara
Freitas de Sá auxiliaram na etapa de
análise de dados e redação.

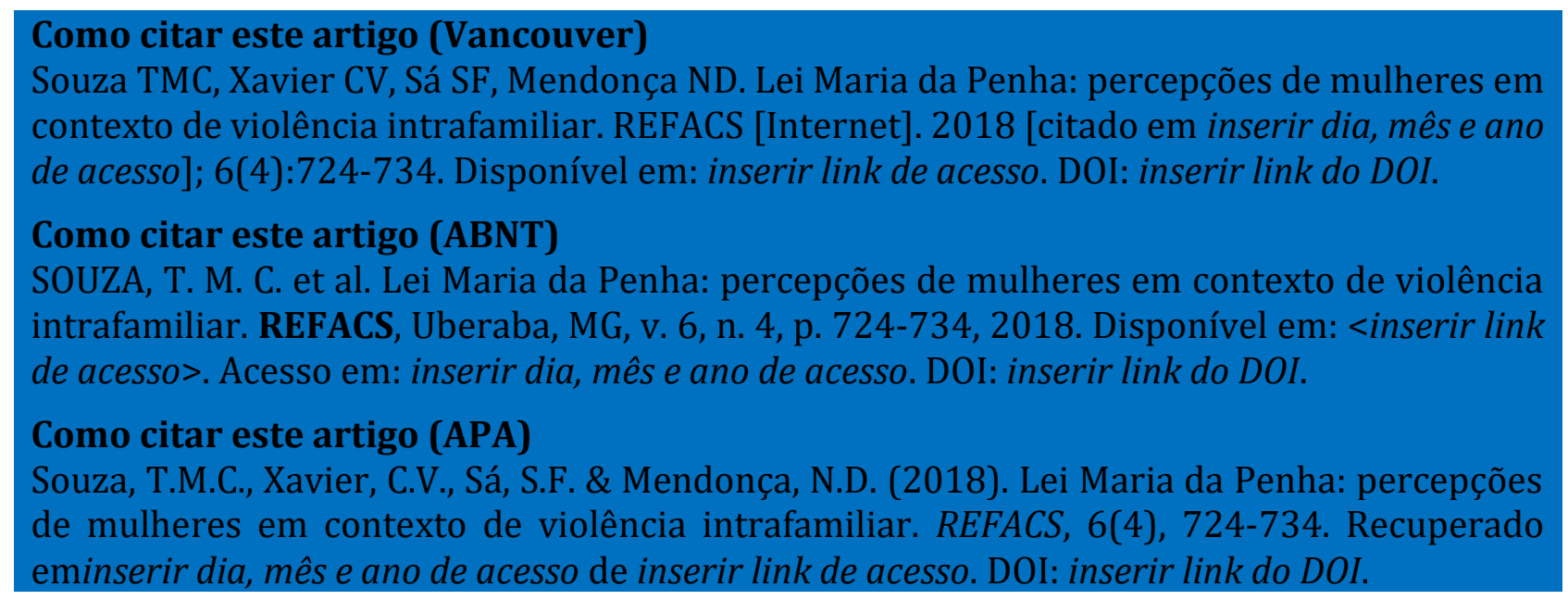

